\title{
SINTESA PEMIKIRAN ULRICH BECK TENTANG RISIKO YANG ADA DI DUNIA DAN SAMANTHA BESSON TENTANG PERTENTANGAN DALAM PEMBENTUKAN HUKUM
}

\author{
Nur Hadiyati \\ Fakultas Hukum, Universitas Internasional Batam \\ Jl. Gajah Mada, Baloi Permai, Kec. Sekupang, Kota Batam, \\ Kepulauan Riau 29442 \\ hadiyati@uib.ac.id
}

\begin{abstract}
The existence of law is a reflection of the condition of a society or community which then agrees to form a law as adegium ibi societa ubi ius is attached to our understanding. However, in fact the agreement behind the formation of the law is a minimum agreement based on the thoughtthinking of tackling the risk of the future, this then becomes interesting to discuss further regarding the minimum agreement based on reasonal disagreement is a thought reviewed by Samantha Besson and thoughts related to risk reviewed by Ulrich. Beck. In order to understand the nature of the formation of the law itself.
\end{abstract}

Keywords: Law; Formation; World Risk; Reasonal Disagreement

\begin{abstract}
Abstrak
Eksistensi hukum merupakan refleksi dari kondisi suatu masyarakat atau komunitas yang kemudian bersepakat untuk membentuk suatu hukum sebagaimana adegium ibi societa ubi ius melekat pada pemahaman kita. Namun sejatinya kesepakatan yang melatarbelakangi pembentukan hukum merupakan kesepakatan minimum yang berlandaskan pada pemikiranpemikaran menanggulangi risiko akan masa depan, hal ini kemudian menjadi menarik untuk dibahas lebih lanjut mengenai kesepakatan minimum adalah sebagai suatu pemikiran yang diulas oleh Samantha Besson dan pemikiran terkait risiko diulas oleh Ulrich Beck. Guna memahami hakikat pembentukan hukum itu sendiri.
\end{abstract}

Kata Kunci: Hukum; Pembentukan; Risiko Dunia; Pertentangan yang Wajar

\section{A. Pendahuluan}

Pembentukan hukum (rechtsvorming) dalam sistem hukum pada hakikatnya ditentukan oleh konsep hukum atau bagaimana pola pikir yang berkembang dalam memandang hukum yang dianut oleh masyarakat dan pembentuknya. Karena orang-orang akan selalu berubah sesuai dengan kondisi. Maka kemudian perlu memahami keadaan atau kondisi yang memiliki keterkaitan dalam pembentukan hukum untuk dapat mengarahkan hingga prosesnya menjadi sebagaimana yang diinginkan.

Hukum dibentuk dari proses pembahasan panjang melalui mekanisme politik, sehingga didalam proses tersebut perlu dipahami apa yang perlu dan tidak diperlukan dalam keberaadan 
pembentukan hukum. Kedua hal yang akan dibahas dalam artikel ini dan penting dalam pembentukan hukum merupakan pertentangan dan pemahaman akan risiko.

Pertentangan adalah perihal bertentangan; perlawanan; perselisihan; pertikaian ${ }^{1}$. Pertentangan merupakan proses interaksi sosial baik antara individu maupun individu dan kelompok dengan maksud dan tujuan memperoleh sesuatu yang diinginkan melalu cara enekan, menghancurkan, atau mengalahkan pihak lawan. Sebab musabab atau akar pertentangan antara lain sebagai berikut $\left.{ }^{2}: 1\right)$ perbedaan antara individu-individu; 2) perbedaan kebudayaan; 3) perbedaan kepentingan; 5) perubahan sosial.

Sedangkan Risiko adalah akibat yang kurang menyenangkan (merugikan, membahayakan) dari suatu perbuatan atau tindakan ${ }^{3}$. Risiko merupakan bagian yang tidak terpisahkan dari kehidupan, Menurut Darmawi, risiko dihubungkan dengan kemungkinan terjadinya akibat buruk (kerugian) yang tidak diinginkan, atau tidak terduga. Dengan kata lain "kemungkinan" itu sudah menunjukkan adanya ketidakpastian. Ketidakpastian itu merupakan kondisi yang menyebabkan tumbuhnya risiko. Kondisi yang tidak pasti itu timbul karena berbagai sebab, yaitu: a) jarak waktu dimulai perencanaan atas kegiatan sampai kegiatan itu berakhir. Makin panjang jarak waktu makin besar ketidakpastiannya, b) keterbatasan tersedianya informasi yang diperlukan, c) keterbatasan pengetahuan atau keterampilan/teknik pengambilan keputusan, dan sebagainya ${ }^{4}$

Memahami eksistensi pertentangan dalam hukum melalui artikel ini akan mengulas pemikiran Samantha Besson. Samantha adalah Profesor di Collège de France, Pemikirannya tentang pertentangan dituangkan dalam buku monograf terbitan Hart Publisher dengan judul The Morality of Conflict: Reasonable Disagreement and Law. Sedangkan berkenaan dengan risiko dipaparkan oleh Ulrich Beck yang merupakan sosiolog Jerman pengemuka istilah masyarakat risiko. Beck pernah menjadi dosen sosiologi Universitas Ludwig-Maximilians Munich sampai 2009, kemudian pindah ke Universitas Munich dan London School of Economics.

Artikel ini hendak menguraikan mengenai pemikiran Samantha Besson tentang Pertentangan Hukum dan Ulrich Beck tentang Risiko, dan bagaimana Teori Hukum Progresif sebagai representatif dari pemikiran Samatha Besson dan Ulrich Beck di Indonesia.

\footnotetext{
Kamus Besar Bahasa Indonesia, diakses dari https://kbbi.kemdikbud.go.id/ Soerjono Soekanto, 1982, Sosiologi Suatu Penganter, Jakarta, PT. Raja Grafindo, hlm 91-92. Kamus Besar Bahasa Indonesia, Op.cit Herman Darmawi, 2006, Manajemen Risiko, Jakarta, Bumi Aksara, hlm. 21
} 


\section{B. Pembahasan}

Samantha Besson dalam bukunya "The Morality of Conflict Reasonable Disagreement and The Law" memberikan pemahaman berkenaan dengan pertentangan wajar tentang keadilan merupakan jalan baru untuk memahami hukum ${ }^{5}$. Hubungan hukum dan pertentangan tidak dapat dikurangi untuk memperlihatkan keadaan alamiah dan lanjutan dan pentingnya pertentangan serta kemunculan prinsip rule of the law yang terlihat secara prosedural, kelembagaan, kontent sebagai hasil yang sempurna dimana hukum memiliki peran untuk menyelesaikan pertentangan dan pertentangan juga memiliki tempat dalam proses pembuatan hukum.

Besson menjabarkan keterkaitan antara hukum dengan pertentangan dan keuntungan yang dapat diperoleh sebagaimana menurut Arendt bahwa pertentangan adalah elemen penting dalam kehidupan manusia. Keseimbangan antara pertentangan dan hukum diperlukan, menurut Dworkin tidak ada pertentangan mengakibatkan hukum stagnan, ada pertentangan mengakibatkan penemuan hukum ${ }^{6}$. Pertentangan memerlukan pengawalan untuk menjaga produkfitiasnya mengakomodir aspirasi dari berbagai kalangan. Maka kemudian dengan segala pemahaman yang ada berkenaan dengan pertentangan maka diperlukan langkah lebih jauh menimbang adanya globalisasi yang menimbulkan banyak sekali perubahan termasuk berkaitan dengan tatanan hukum, bahwa menurut Hume hubungan akan pertentangaan dan keinginan untuk bersatu (konvergen) semakin meningkat seperti yang terjadi pada masyarakat barat dengan tiga isu utama yang dipaparkan Besson yakni berkenaan dengan kedaulatan, koherensi, dan kewarganegaraan.

Kondisi global ini yang kemudian dipaparkan secara cukup baik oleh seorang pakar sosiolog yaitu Ulrich Beck dalam karyanya yang berjudul World at Risk dengan maksud dari penulisan mengambarkan bahwa dunia memiliki bahaya tersendiri yang dapat dicegah atau tanggulang atau dengan pembentukan hukum baru, sebagai contoh dari beberapa kasus yang dipaparkan Beck adalah berkenaan dengan sebuah upaya terorisme dengan zat peledak cair/liqiud dipesawat Heathrow menuju United States pada 2006 yang berhasil digagalkan, 3 bulan setelah kejadian Uni-Eropa membuat peraturan pencegahan kejadian serupa dengan mengatur berkenaan dengan pembawaan zat cair/liqiud dipesawat. Namun, jika telusur mendalam bahwa keputusan berkenaan risiko bukan hanya sekadar pilihan berisiko dan tidak berisiko, melainkan pilihan diantara hal-hal yang tidak berisiko, dan tidak jarang memilih risiko dengan perhatian kualitatif beda dimensi.

5 Samantha Besson, 2005, The Morality of Conflict : Reasonable Disagreement and The Law, Hart Publishing, hIm 532

6

Ibid 
Demikianlah hidup berjalan diantara ancaman dan rasa ketidamanan, hal ini yang melahirkan pengistilah risiko (semantic risk) yang harus dipahami secara terpisah karena terjadi bukan secara alamiah. Istilah risiko (semantic risk) merujuk pada pemetaan dari ancaman masa depan yang kerapkali menghasilkan kesuksesan dalam membentuk peradaban-post utopia ${ }^{7}$. Risiko selalu bergantung pada keputusan yang merupakan transofrmasi ketidakpastian dan bahaya, ancaman tak terhitung pada masyarakat pre-industrial (wabah, kelaparan, perang, tuhan, setan, dII) berubah menjadi risiko yang terhitung dalam perkembangan instrumen kontrol rasional yang merupakan proses modernisasi diseluruh ruang kehidupan ${ }^{8}$. Gagasan risiko selalu memiliki makna negatif karena pemaknaannya terhadap kesempatan untuk menghindari hal yang tidak diinginkan, namun pemaknaan ini dapat juga berubah menjadi positif ketika merupakan sebuah instiatif untuk menghadapi permasalahan dimasa yang akan datang, orang yang sukses memahami dan mengambil risiko sangatlah dikagumi ${ }^{9}$. Pengkategorian risiko tergantung perspektikf dan sangat luas diantara tahu dan ketidaktahuan, benar dan salah, baik dan buruk, maka publik memandang perlu untuk mempelajari dan memahami tentang risiko dengan masyarakat yang bernegosiasi ulang didalamnya,

Berbicara berkenaan tentang masyarkat yang terdampak oleh risiko (risk society) adalah masyarakat dimana kita hidup dengan meningkatnya teknologi dan tidak ada satupun yang memahami secara pasti atau mengartikan keanekaragaman kemunginkan yang terjadi dimasa depan. Asal dari masyarkat yang terdampak oleh risiko (risk society) dapat dilihat dapat dua hal yang fundamental yakni berakhirnya keadaan alamiah (the end of nature) dan berakhirnya hal tradisional seperti keyakinan dst (the end of tradition) ${ }^{10}$. Pemahaman berkenaan dengan risk society ini kemudian berkembang secara global dan tersistematis (world risk society). Beck berbicara risiko dan perkembangannya yang dapat disimak pada tabel $1 .{ }^{11}$

7 Gagasan utopia diperkenalkan oleh Thomas More yakni sebuah fiksi berkenaan kondisi masyarakat yang sempurna dengan prinsip kepemilikan bersama, toleransi beragama, kesetaraan gender, kesejahteraan sosial, dst, berasal dari bahasa yunani "ou-topos" atau "eu-topos" dengan penafsiran tempat yang baik atau tiada tempat untuk menunjukkan bahwa kondisi masyarakat yang sempurna tersebut tidak ada dalam kondisi saat ini melainkan bayangan masa depan. Sedangkan yang dimaksud dengan post-utopia adalah keadaan setelah tercapainya utopia atau beberapa orang justru mengartikan sebagai kondisi pencarian utopia itu sendiri.

8 Darryl S.L Jarvis, 2016, Theorizing Risk: Ulrich Beck, Globalization and the Rise of the Risk Society, Singapore, Lee Kuan Yew School of Public Policy National University of Singapore, hlm 16

9 Anthony Giddens, 1999, Risk and Responsibility, The Modern Law Review Vol 62 No.1, hlm 3

10 Ibid

11 Darryl S.L Jarvis, Op.cit, hlm 20 
Tabel 1.

Perkembangan Risiko di Masyarakat

\begin{tabular}{|c|c|c|c|}
\hline & Pre-Modern & $\begin{array}{l}\text { Masyarakat Industri } \\
\text { (Modernity) }\end{array}$ & $\begin{array}{c}\text { Masyarakat terdampak } \\
\text { Risiko (Reflexive } \\
\text { Modernity) }\end{array}$ \\
\hline Bentuk Risiko & Keputusan & Perhitungan & Radikal \\
\hline Asal Risiko & $\begin{array}{l}\text { Bahaya alam dan } \\
\text { bencana (gempa, } \\
\text { longsor, banjir, } \\
\text { penyakit, cuaca } \\
\text { ekstrim, dll) }\end{array}$ & $\begin{array}{l}\text { Bahaya } \text { alam asosiasi } \\
\text { dengan risiko ditempat } \\
\text { kerja seperti risiko } \\
\text { pengoperasian alat atau } \\
\text { teknologi }\end{array}$ & $\begin{array}{l}\text { Bencana buatan, risiko } \\
\text { dihasilkan dari kondisi sosial, } \\
\text { politik, ekonomi, organisasi } \\
\text { berasal dari pengoprasian } \\
\text { teknologi }\end{array}$ \\
\hline \multirow[t]{2}{*}{$\begin{array}{l}\text { Risiko/Bahaya } \\
\text { berfungsi sebagai } \\
\text { keputusan } \\
\text { individu }\end{array}$} & $\begin{array}{l}\text { Tidak (tuhan, } \\
\text { setan), } \\
\text { Berdasarkan } \\
\text { pengamatan } \\
\text { bahwa bahaya } \\
\text { merupakan } \\
\text { kehendak alam } \\
\text { vang tidak bisa }\end{array}$ & $\begin{array}{l}\text { lya. Risiko adalah dari } \\
\text { kegiatan industri dan } \\
\text { proses didalamnya serta } \\
\text { hasilnya (menyetir, } \\
\text { terbang, kecelakaan } \\
\text { kerja, kecelakaan mesin, } \\
\text { makanan kadaluarsa) }\end{array}$ & \multirow[t]{2}{*}{$\begin{array}{l}\text { Tidak, secara kolektif } \\
\text { mengambil keputusan } \\
\text { berdasarkan adaptasi, } \\
\text { perkembangan, penerapan } \\
\text { teknologi terkait individu dan } \\
\text { masyarakat. Berbasiskan } \\
\text { pengetahuan tanpa bisa } \\
\text { mengontrol risiko yang dapat } \\
\text { ditimbulkan }\end{array}$} \\
\hline & dicegah & $\begin{array}{lr}\text { Keputusan } & \text { adalah } \\
\text { bagaimana } & \text { mana } \\
\text { mempergunakan } & \text { produk } \\
\text { teknologi } & \end{array}$ & \\
\hline $\begin{array}{l}\text { Lingkup } \\
\text { kehancuran }\end{array}$ & $\begin{array}{l}\text { Orang, kota, } \\
\text { negara, budaya }\end{array}$ & $\begin{array}{l}\text { Tergantung pada ruang, } \\
\text { waktu, batasan sosial } \\
\text { atau perhitungan politik } \\
\text { yang ditannggulangi } \\
\text { dengan pengantian rugi } \\
\text { dan jaminan }\end{array}$ & $\begin{array}{l}\text { Tidak terbatas karena } \\
\text { umumnya risiko tidak dapat } \\
\text { diantisipasi }\end{array}$ \\
\hline $\begin{array}{l}\text { Perhitungan } \\
\text { kehancuran }\end{array}$ & Tidak pasti & $\begin{array}{l}\text { Dapat dihitung, dan ada } \\
\text { kepastian hukum serta } \\
\text { pertanggungjawaban }\end{array}$ & $\begin{array}{l}\text { Sangat kecil, karena } \\
\text { kehancuran bersifat tidak } \\
\text { terbatas sehingga tidak ada } \\
\text { perhitungan }\end{array}$ \\
\hline $\begin{array}{l}\text { Pertangungjawab } \\
\text { an }\end{array}$ & $\begin{array}{l}\text { Takdir, } \\
\text { supranatural }\end{array}$ & $\begin{array}{l}\text { Aturan penugasan } \\
\text { melalui politik, institusi, } \\
\text { hukum }\end{array}$ & $\begin{array}{l}\text { Tidak ada kepastian hukum } \\
\text { Ya atau tidak, "Tidak } \\
\text { bertanggungjawab secara } \\
\text { teroganisir" ketidakmapuan } \\
\text { lembaga institusi politik untuk } \\
\text { merespon refleks modern } \\
\text { dari sebuah risiko }\end{array}$ \\
\hline
\end{tabular}

Demikian bentuk dari risiko yang ingin Beck pahamkan melalui bukunya dengan kemudian diuji terhadap tiga logika dalam risiko yang dibedakan menjadi konteks ekonomi, lingkungan, dan risiko secara global. Harapan dari pemahaman ini adalah mampunya untuk menghindari dampak kehancuran yang tidak terbayangkan dari risiko melalui pengambilan keputusan-keputusan dari pilihan - pilihan yang ada. Kondisi masyarakat terdampak risiko 
adalah kondisi masyarakat saat ini menutur Slavoj Zizek ${ }^{12}$ yang berdasarkan penghapusan otoritas dari atas (the big other). Namun terdapat permasalahan menurut Zizek ketika menganti otoritas dengan pilihan atas keputusan dimana teori masyarakat terdampak risiko dapat menimbulkan paranoia atau narsisisme sehingga untuk mengatasi patalogi ini Zizek menawarkan adanya sebuah tindakan politik atau revolusi dengan melahirkan tipe baru yang menjadi simbolik.

Semangat pembaharuan dengan memperhatikan keberadaan pertentangan sebagai pembentuk hukum sebagaimana dipaparkan Besson dan ditambah dengan pemahaman kondisi global dengan risiko yang dipaparkan oleh Beck menjadikan hukum lebih berfungsi bukan hanya pada saat sekarang namun juga bersifat akan datang yakni probabilitas untuk menjawab kebutuhan masyarakat akan keadilan. Jerome Frank berkata bahwa tugas dari realis hukum (legal realist) adalah untuk membuat hukum lebih responsif kepada kebutuhan sosial ${ }^{13}$. Konsep hukum responsif dibicarakan oleh Nonet dan Selznick sebagai tahap dari bagian perubahan hukum sebelumnya yakni hukum reprepsif dan hukum otonomi atau menurut Weber sebagai rasional formal. Nonet dan Selznick mendeskripsikan kemunculan dari hukum responsif memiliki kesamaan dengan ide di eropa berkenaan dengan rematerialisasi hukum formal namun dengan model yang lebih koheren dan sistematik ${ }^{14}$. Hukum responsif memiliki sifat untuk mempertahankan hal yang esensial untuk diintegrasikan dengan kondisi baru pada lingkungan dimana tekanan sosial menjadi sumber pemahaman untuk pembenaran hukum itu sendiri, terdapat ruang perdebatan, perubahan, dan penyesuaian didalamnya. Pemikiran hukum responsif yang diutarakan oleh Nonet dan Selznick merupakan bagian dari tradisi pemikiran sociological jurisprudence yang dikemukan oleh Roscoe Pound dan didukung pendapaf secara filosofis oleh Dworkin dan John Dewey ${ }^{15}$.

Hukum yang responsif dapat dilihat dari adanya pemikiran hukum progresif yang dalam literatur pendidikan hukum di Indonesia dicetuskan oleh Sajipto Raharjo. Hukum progresif merupakan koreksi terhadap kelemahan sistem hukum modern sarat dengan birokrasi serta ingin membebaskan diri dari dominasi suatu tipe hukum liberal, tujuannya agar para penegak hukum tidak melihat suatu peraturan atas apa yang tertulis saja ${ }^{16}$.

12 Tony Myers, 2003, Slavoz Zizek, London, Routledge - Psychology Press, hlm 61

13 Philippe Nonet dan Philip Selznik, 1987, Law and Society in Transition Toward Responsive Law, New Brunswick: Transaction Publisher, hlm 117

14 Gunther Teubner, 1983, Substantive and Reflexive in Modern Law, Law \& Society Review Vol.17 No.2, hlm 251

15 Malcom M.Feeley, Book Review - Law, Legitimacy and Symbols : An Expanded View of Law and Society in Transition, Michigan Law Review Vol 77, 1979, hlm 900

16 A.Sukris Sarmadi, Membebaskan Positivisme Hukum ke Ranah Hukum Progresif (Studi Pembacaan Teks Hukum bagi Penegak Hukum), Jurnal Dinamika Hukum Vol. 12 No 2, Mei 2012, hlm 334 
Memahami istilah progresivisme dalam konteks hukum progresif dapat dijabarkan sebagai berikut $^{17}$ : 1) Progresivisme bertolak dari pandangan bahwa pada dasarnya manusia adalah baik, dengan demikian hukum progresif mempunyai kandungan moral yang kuat. Progresivisme ingin menjadikan hukum sebagai institusi yang bermoral; 2) Hukum progresif mempunyai tujuan berupa kesejahteraan dan kebahagiaan manusia, maka sebagai konsekuensinya hukum selalu dalam proses menjadi. Oleh karena itu hukum progresif selalu peka terhadap perubahan masyarakat di segala lapisan; 3) Hukum progresif mempunyai watak menolak status quo ketika situasi ini menimbulkan kondisi sosial yang dekanden dan korup. Hukum progresif memberontak terhadap status quo, yang berujung pada penafsiran hukum yang progresif; 4) Hukum progresif mempunyai watak yang kuat sebagai kekuatan pembebasan dengan menolak status a quo.

Paradigma "hukum untuk manusia" membuatnya merasa bebas untuk mencari dan menemukan format, pikiran, asa, serta aksi yang tepat untuk mewujudkannya Untuk menuju hukum progresif hukum diprinsipkan dalam konsep sebagai berikut ${ }^{18}$. Pertama, asumsi dasar hukum haruslah untuk manusia bukan untuk dirinya sendiri hukum itu diadakan; kedua, hukum progresif tidak menerima hukum sebagai institusi yang mutlak serta final; ketiga, hukum tidak boleh melepaskan dirinya dari tujuan sosial; keempat, hukum mengabdi kepada manusia karenanya tidak boleh mengabaikan hati nurani manusia; kelima, hukum harus bermoral; keenam, hukum progresif merupakan koreksi terhadap kelemahan sistem hukum modern; ketujuh, hukum harus selalu berada dalam proses untuk terus menjadi; kedelapan, hukum progresif menolak tradisi analytical jurisprudence atau rechtsdogmatiek dan berbagai paham atau aliran yang tidak berkesesuaian dengan konsep keadilan; kesembilan, interpretasi hukum progresif dengan hati nurani, melihat hukum bukan hanya dalam dataran yang tertulis dari teks formalnya; kesepuluh hukum progresif menerima hukum bukan hanya pada internal hukum itu sendiri tetapi lebih luas.

Satjipto Rahardjo tidak menjelaskan bagaimana Hukum Progresif dapat diterapkan dalam sistem hukum di Indonesia ${ }^{19}$. Namun setidaknya eksistensi hukum progresif menjadi jembatan dalam kesenjangan hukum (legal-gap) yang terjadi karena kondisi masyarakat yang dinamis sedangakan senantiasa berproses sedangkan kaidah kehidupan terpaku dalam Produk legislasi yang diposisikan sebagai salah satu objek paling resprensentif dari hukum hanya mematri kondisi masyarakat pada suatu waktu tertentu saja. Kesenjangan hukum (legal-gap) merupakan

17 Mahmud Kusuma, 2009, Menyelami Semangat Hukum Progresif : Terapi Paradigma bagi Lemahnya Hukum Indonesia, Yogyakarta : AntonyLib, hlm 60

18 A.Sukris, Op.cit, hlm 335-336

19 Deni Nuryadi, Teori Hukum Progresif dan Penerapannya di Indonesia, Jurnal Ilmiah Hukum De'Jure: Kajian IImiah Hukum Vol.1 No.2, 2016, hlm 406 
kemungkinan dimana produk legislasi sebagai hukum positif ini tidak secara tepat mampu menjawab kebutuhan dalam peristiwa konkret.

Teori hukum progresif adalah pandangan yang tepat dalam mengkaji hukum, hukum progresif tidak hanya memandang Hukum dari segi positivisme melainkan juga memandang hukum sebagai kenyataan sosial, Memandang hukum bukan semata-mata sebagai UndangUndang Produk Kekuasaan, tetapi produk sosial, memandang hukum tidak berada di ruang hampa, tetapi dalam realitas kehidupan nyata, jika hukum normatif cenderung pada Quid Juris (Normatif, Sollen), tetapi teori hukum progresif Cenderung Pada Quid Facti/Alamiah, (Empiris/Sein) $^{20}$. Dan agar hukum progresif dapat berkembang sebagaimana mestinya di Indonesia mencapai tujuannya secara maksimal dalam menciptakan keadilan dan kebahagiaan bagi masyarakat sebagaimana termaktub dalam tujuan nasional, maka diperlukan kondisi yang akan mengantarkan atau memudahkan Hukum Progresif mencapai tujuan tersebut, yaitu ${ }^{21}:$ 1) Tersedianya hukum substantive yang mengandung asas keadilan dan pro kepada rakyat; 2) Sistem Peradilan yang mendukung rakyat pencari keadilan untuk memperoleh keadilan hakiki di ruang pengadilan; 3) Para penegak hukum (penyidik, jaksa, hakim dan advokat) yang memiliki "kemumpunian" nalar dan hati nurani, intelektual dan moral. Termasuk di sini pemahaman hukum dan moral dari para pencari keadilan; 4) Fasilitas atau "dapur" yang memadai dan kompeten untuk menciptakan para penegak hukum yang memiliki kemampuan intelektual dan sekaligus moral untuk memberikan keadilan yang hakiki kepada pencari keadilan

Pertentangan berbicara tentang pengetahuan sedangkan Risiko adalah narasi ironi berhubungan dengan satir yang tidak disengaja, rasa optimis sia-sia, hal-hal yang dihasilkan oleh institusi dimasyarakat modern untuk mengantisipasi apa yang tidak dapat diantisipiasi sebagaimana bingkai adegium socrates "aku tahu bahwa aku tidak tahu apapun"22. Diluasnya fakta yang membentang kita terus berupaya memahami pemikiran dan penyikapan dari pemikiran dengan filsafat, "secundum nominis etymologiam philosophia idem est atque amor seu studium saplentiae". Menurut etimologi perkataannya maka filsafat adalah sama dengan cinta atau mintat pada kebijaksanaan.

\section{Simpulan}

Pembentukan hukum (rechtsvorming) dalam sistem hukum pada hakikatnya ditentukan oleh konsep hukum atau bagaimana pola pikir yang berkembang dalam prosesnya. Dua hal

20 Satria Sukananda, Pendekatan Teori Hukum Progresif dalam Menjawab Permasalahan Kesejangan Hukum (Legal Gaps) Di Indonesia, Jurnal Hukum Ekonomi Syariah Vol.1 No.2, 2018, hlm 139

21 Deni Nuryadi, Op.Cit, hlm 407

22 Ulrich Beck, Living in The World Risk Society, Economy and Society Vol. 35 No. 3, 2006, hlm 329 
yang perlu dipahami dalam pembentukan hukum adalah berkaitan dengan pertentangan dan risiko.

Samantha Besson dalam bukunya "The Morality of Conflict Reasonable Disagreement and The Law" memberikan pemahaman berkenaan dengan pertentangan wajar tentang keadilan merupakan jalan baru untuk memahami hukum. Sedangkan Ulrich Beck memaparkan risiko sebagai dalam karyanya yang berjudul World at Risk dengan maksud meliharkan risiko sebagai bahaya yang melekat dengan dunia yang dapat dicegah atau tanggulang atau dengan pembentukan hukum baru.

Pemahaman akan bagaimana mengakomodir pertentangan dan risiko ini dalam kajian literatur dikenal dengan Hukum Progresif yang diutarakan oleh Sajipto Raharjo. Hukum progresif merupakan koreksi terhadap kelemahan sistem hukum modern sarat dengan birokrasi serta ingin membebaskan diri dari dominasi suatu tipe hukum liberal, tujuannya agar para penegak hukum tidak melihat suatu peraturan atas apa yang tertulis saja. Satjipto Rahardjo tidak menjelaskan bagaimana Hukum Progresif dapat diterapkan dalam sistem hukum di Indonesia. Namun setidaknya eksistensi hukum progresif diharapkan dapat menjadi jembatan dalam kesenjangan hukum (legal-gap) yang terjadi karena kondisi masyarakat yang dinamis

\section{DAFTAR PUSTAKA}

\section{Buku:}

Besson, Samantha. 2005. The Morality of Conflict : Reasonable Disagreement and The Law. Oxford: Hart Publishing

Darmawi, Herman. 2006. Manajemen Risiko. Jakarta: Bumi Aksara

Kamus Besar Bahasa Indonesia, diakses dari https://kbbi.kemdikbud.go.id/

Kusuma, Mahmud. 2009. Menyelami Semangat Hukum Progresif : Terapi Paradigma bagi Lemahnya Hukum Indonesia. Yogyakarta : AntonyLib,

Myers, Tony. 2003. Slavoz Zizek. London: Routledge - Psychology Press

Nonet, Philippe dan Selznik, Philip. 1987. Law and Society in Transition Toward Responsive Law. New Brunswick: Transaction Publisher

S.L Jarvis, Darryl. 2016. Theorizing Risk: Ulrich Beck, Globalization and the Rise of the Risk Society. Singapore : Lee Kuan Yew School of Public Policy National University of Singapore

Soekanto, Soerjono. 1982. Sosiologi Suatu Pengantar. Jakarta : PT. Raja Grafindo 


\section{Jurnal:}

Beck, Ulrich Living in The World Risk Society, Economy and Society Vol. 35 No. 3, 2006

Giddens, Anthony. 1999. Risk and Responsibility, The Modern Law Review Vol 62 No.1

M.Feeley, Malcom. Book Review - Law, Legitimacy and Symbols : An Expanded View of Law and Society in Transition. Michigan Law Review Vol 77, 1979

Nuryadi, Deni. Teori Hukum Progresif dan Penerapannya di Indonesia. Jurnal IImiah Hukum De'Jure: Kajian IImiah Hukum Vol.1 No.2 , 2016

Sarmadi, A.Sukris. Membebaskan Positivisme Hukum ke Ranah Hukum Progresif (Studi Pembacaan Teks Hukum bagi Penegak Hukum). Jurnal Dinamika Hukum Vol. 12 No 2, Mei 2012

Sukananda, Satria. Pendekatan Teori Hukum Progresif dalam Menjawab Permasalahan Kesejangan Hukum (Legal Gaps) Di Indonesia. Jurnal Hukum Ekonomi Syariah Vol.1 No.2, 2018

Surtz, Edward L. Interpretation of Utopia, The Catholic Historical Review, Vol. 38, No. 2 (Jul., 1952

Teubner, Gunther. 1983. Substantive and Reflexive in Modern Law, Law \& Society Review Vol.17 No.2

Ulrich Beck, Critical Theory of World Risk Society: A Cosmopolitan Vision,Constellations Volume 16, No 1, 2009. 